\title{
An Observational Study On The Spectrum Of Heat-Related Illness, With A Proposal On Classification
}

\author{
TK Day, D Grimshaw
}

\begin{abstract}
During operations in subtropical areas over the summer months of 2001 and 2003 the authors audited 80 patients with heat-related illness, with the intention of defining the nature and distribution of the underlying pathophysiology. Haematological, biochemical and clinical data were gathered prospectively and patients allocated to diagnostic categories on the basis of the combination of clinical findings and investigations. Four basic types of heatrelated illness could be distinguished: (1) excessive salt loss with hyponatraemic dehydration, (2) hypokalaemic alkalosis with low serum bicarbonate, (3) haemodilution associated with excessive water intake in stressed individuals, and (4) loss of normal thermoregulation, characterised by high core temperature and paradoxical cessation of sweating. Most of the patients fell clearly into a single distinct category, but there was a degree of overlap. Reduction of extracellular fluid volume was a common central mechanism. Common provoking factors identified were: gastrointestinal upset, history of previous heat intolerance (35\%) environmental temperatures exceeding $45^{\circ} \mathrm{C}$, short period of acclimatisation (55\%), travel, sleep loss, hard physical work especially if directly preceded by a period of sleep, work in confined humid spaces (45\%), and lack of additional salt intake. When several of these factors were present together admission rate over one 24 -hour period reached $3 \%$ of persons at risk per day. Patients are often more ill than they appear. To reduce the incidence of heat illness during future operations the following measures are proposed:
\end{abstract}

Wg Car T K Day MA MChir MRCP FRCS RAuxAF

Consultant Surgeon

TPMH, RAF Akrotiri

Cpl D Grimshaw MSc FIBMS RAuxAF

Chief Laboratory

Medical Scientific

Officer

612 Sqn RAF Leuchars Fife relieve thirst and to ensure the flow of abundant dilute urine.

\section{Introduction}

Heat-related illness may be used to describe a group of disorders resulting from the exposure of individuals to high environmental temperatures. This definition excludes illness not directly caused by heat, for example, infective diarrhoea and vomiting, although the two illnesses may occur in the same setting. Various terms have been used to describe the range of pathology associated with heat exposure such as heat exhaustion, heat stroke, heat cramps heat syncope etc., but these terms, although descriptive of certain symptoms, do not appear to have any unique pathological basis (1), nor do these diagnostic categories guide treatment or suggest preventative strategies. A categorisation based purely on core temperature and evidence of organ damage as proposed in JSP 539 (2) which provides essential guidance for the management of heat illness in temperate climates, would exclude a considerable body of pathology seen in hot countries that is heat-related, and which may be associated with serious illness.

The object of the present study was to gather clinical and biochemical data from a group of individuals who had become ill after being subjected to high environmental temperatures with a view to identifying and categorising the underlying pathology, and thereby providing an insight into prevention and treatment.

\section{Methods}

\section{Population studied}

The population studied consisted of a total of 80 individuals presenting to Role 2 and Role $2+$ facilities (primary care units with some inpatient accommodation and laboratory facilities) during operations in Oman and Iraq during the summer months of 2001 and 2003. The cases studied arose from a varying and often transitory population. During the period of this study, peak daily environmental temperatures were in the range 43 to $52^{\circ} \mathrm{C}$, with night time minimum temperatures of 27 to $32^{\circ} \mathrm{C}$ and wind speeds of $10-25$ knots. Wet bulb globe temperatures and relative humidities were not available in the areas where the study was undertaken.

The catchment area of the study involved a population at risk of between approximately 1000 and 2000 persons. This population was not necessarily typical of the overall 
population of military personnel at risk during the operations in question, because the facilities were located close to where troops would arrive in theatre.

\section{History and clinical findings}

In all cases the history, clinical findings and laboratory results were recorded on a standardised proforma. Specific enquiry was made for the following symptoms: fatigue, cramps, paraesthesia, intestinal colic, vomiting, nausea, diarrhoea, constipation, headache, retro-orbital pain, dyspnoea, confusion, dizziness, and vertigo. Any unusual or additional symptoms were recorded. Clinical measurements were: resting pulse, blood pressure standing and lying, recumbant pulse pressure, respiratory rate, rectal temperature, tissue turgour (as judged by eye turgour to gentle palpation) and the presence or absence of sweating in the normally moist areas of the axillae and groins. Basic biochemistry and haematology was performed using an I-STAT (Abbott) auto analyser and urine specific gravity by Labstix. Further assay parameters, where indicated, were performed in the nearby field hospital, using an Ektachem autoanalyser (Johnson and Johnson). The I-STAT was operated within the parameters set down by the manufacturers and was validated by checking 20 samples with the autoanalyser at the nearby Field Hospital. As a control group, anonymised samples were studied which had been given during a course of practice in cannulation by 21 acclimatised asymptomatic individuals of the same age range as the study group.

\section{Data and statistics}

Normal ranges for biochemical values were established using the control group of 21 age-matched subjects, the normal range being taken as two standard deviations either side of the mean. Results were collated on standardised tables, and selection criteria applied to sort out the pathological processes underlying the heat illness as follows: extracellular fluid depletion was identified when the patient showed evidence of hypovolaemia characterised by tachycardia and postural hypotension associated with reduced tissue turgour and elevation of the $\mathrm{Hb}>16 \mathrm{~g} \%$ reversible by IV fluids. Hypokalaemia was identified when the serum potassium concentration was $<3.7 \mathrm{mM} / \mathrm{L}$, hyponatraemia when the serum sodium concentration fell below $135 \mathrm{mM} / \mathrm{L}$ and alkalosis when the blood $\mathrm{pH}$ exceeded 7.45. Paradoxical dilutional states were identified when the patient had a serum urea concentration of $<3.6 \mathrm{mM} / \mathrm{L}$ in the presence of a urine concentration >SG1020. Statistical comparisons were performed by comparison of variance and Chi tests.

\section{Results}

There were no deaths and 3 ITU admissions out of those with type 4 illness during the period of the study. 28 cases required evacuation up the medical chain because of repeated episodes of heat illness, failure to heat adapt or suspicion of heat induced organ damage evidenced by abnormal liver function tests or elevated creatinine kinase (CK).

\section{Types of illness}

Four types of heat illness could be distinguished: hyponatraemic dehydration, hypokalaemia with alkalosis, paradoxical haemodilution, and loss of normal thermoregulation. The clinical features of these various presentations are illustrated in Table 1. Table 2 illustrates the range and distribution of clinical and laboratory findings within the different categories of heat illness; the average values for the normal control group is in parentheses. There is some degree of overlap between the categories; this is illustrated in the form of a Venn diagram (Figure 1) within which the patients have been plotted as a scattergram.

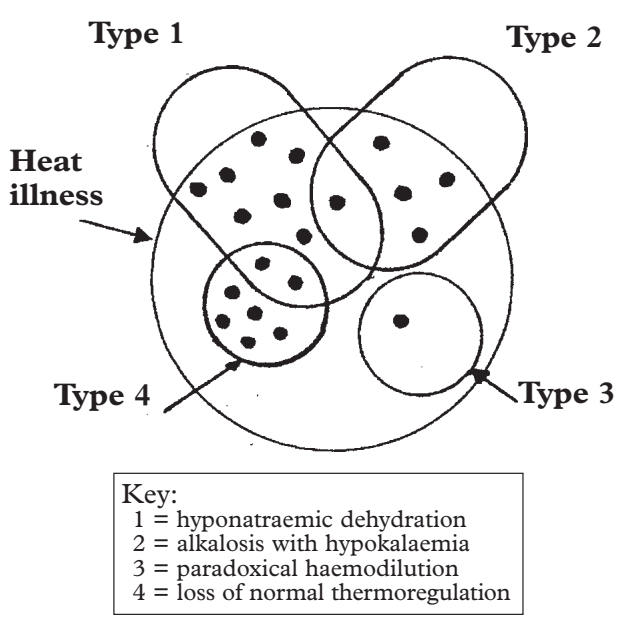

Fig 1. Postulated mechanisms in heat illness.

The Venn diagram demonstrates how heat illness (outline circle) embraces loss of normal thermoregulation and paradoxical haemodilution (which appears to be due to a combination of excess water intake combined with a stressinduced antidiuretic stimulus), whilst the picture of hypokalaemic alkalosis and that of hyponatraemic dehydradration is not exclusive to heat illness, also being seen in such conditions as pyloric stenosis, diuretic abuse and salt loosing nephropathy. There is a degree of overlap between hyponatraemic dehydration and hypokalaemic alkalosis. Loss of thermoregulation may occur on a background of hyponatraemic dehydration. In the diagram groups of 4 patients from the present series are plotted as single dots, to give an idea of the degree of overlap between the different categories.

\section{Hyponatraemic dehydration}

These patients were not thirsty, and normally presented with a combination of gastrointestinal symptoms (nausea, vomiting, colicky abdominal pain and diarrhoea) and of malaise (dizziness, light-headedness, fatigue). Cramps were present in $36 \%$. They had a tachycardia and soft eyeballs. Postural 
Table 1. Clinical features of the 4 proposed categories of heat-related illness.

\begin{tabular}{|c|c|c|c|}
\hline $\begin{array}{l}\text { Hyponatraemic } \\
\text { dehydration }\end{array}$ & $\begin{array}{l}\text { Hypokalaemic } \\
\text { alkalosis }\end{array}$ & $\begin{array}{l}\text { Haemodilution } \\
\text { thermoregulation }\end{array}$ & Loss of normal \\
\hline $\begin{array}{l}\text { Unacclimatised; } \\
\text { sodium and } \\
\text { potassium-rich sweat }\end{array}$ & $\begin{array}{l}\text { Tachypnoeic } \\
\text { response to } \\
\text { heat stress }\end{array}$ & $\begin{array}{l}\text { Excessive water } \\
\text { intake; insufficient } \\
\text { salt; stress (travel, } \\
\text { recent arrival). } \\
\text { Recent previous } \\
\text { heat illness }\end{array}$ & $\begin{array}{l}\text { Vigorous exercise in } \\
\text { hot environment; } \\
\text { insufficient water/ } \\
\text { salt intake, } \\
\text { fatigue, recent } \\
\text { sleep/fasting }\end{array}$ \\
\hline $\begin{array}{l}\text { Dizziness, weakness, } \\
\text { fatigue, nausea, } \\
\text { cramps, vomiting, } \\
\text { intestinal colic, } \\
\text { diarrhoea }\end{array}$ & $\begin{array}{l}\text { Dyspnoea, } \\
\text { excitability, } \\
\text { agitation, } \\
\text { paraesthesia, } \\
\text { cramps, colic }\end{array}$ & $\begin{array}{l}\text { Confusion, } \\
\text { headache, sudden } \\
\text { loss of consciousness, } \\
\text { dizziness, fits, } \\
\text { respiratory arrest }\end{array}$ & $\begin{array}{l}\text { Malaise, fatigue, } \\
\text { nausea and } \\
\text { vomiting dizziness, } \\
\text { confusion, collapse }\end{array}$ \\
\hline $\begin{array}{l}\text { Tachycardia, } \\
\text { postural } \\
\text { hypotension, } \\
\text { soft eyeballs }\end{array}$ & $\begin{array}{l}\text { Tachypnoea, } \\
\text { postural } \\
\text { hypotension, } \\
\text { reduced pulse } \\
\text { pressure, carpal } \\
\text { spasm }\end{array}$ & $\begin{array}{l}\text { Paradoxical } \\
\text { increase } \\
\text { in urine specific } \\
\text { gravity } \\
\text { Systolic } \\
\text { hypertension }\end{array}$ & $\begin{array}{l}\text { Hot dry skin. } \\
\text { Injected } \\
\text { conjunctivae, } \\
\text { Tachycardia, } \\
\text { Rectal temperature } \\
>38.50 \text { C. } \\
\text { Reduced } \\
\text { level of } \\
\text { consciousness, } \\
\text { Myoglobinuria }\end{array}$ \\
\hline Low $\mathrm{Na}$ & Low $\mathrm{Na}$ & Low $\mathrm{Na}$ & $\begin{array}{l}\text { Elevated urea, } \\
\text { creatinine }\end{array}$ \\
\hline Low $\mathrm{K}$ & Low $\mathrm{K}$ & Low $\mathrm{K}$ & $\begin{array}{l}\text { Transaminases, CK, } \\
\text { LDH elevated }\end{array}$ \\
\hline Elevated urea & High $\mathrm{pH}$ & Low/normal urea & Normal or high $\mathrm{K}$ \\
\hline Elevated haematocrit & $\begin{array}{l}\text { Normal or elevated } \\
\text { haematocrit }\end{array}$ & Normal haematocrit & Normal or low $\mathrm{pH}$ \\
\hline
\end{tabular}

hypotension occurred when estimated ECF loss judged by haemoconcentration exceeded about 1.5L. Haemoconcentration with haemoglobin levels as high as $22 \mathrm{~g} \%$, were observed and patients would require replacement of between 1.5 and 7 litres of isotonic saline before regaining normal hydration, as judged by a urine output in excess of $30 \mathrm{ml} / \mathrm{hr}$ and restoration of normal eyeball tonicity. Rectal temperature was no guide to the severity of the biochemical abnormality or to the subsequent course of the illness.

Hyponatraemic dehydration accompanied by hypokalaemic alkalosis

A frequently seen variation of hypotonic dehydration seen in those with high respiratory rates $(>24 / \mathrm{min})$ and symptoms of agitation or anxiety, was a respiratory alkalosis with associated hyponatraemia and hypokalaemia. The mean serum potassium concentration was lower in these patients $(2.8 \mathrm{cf} 3.2, \mathrm{p}<0.05)$, and this was associated with an inappropriate diuresis, probably secondary to hypokalaemic distal tubular dysfunction in $25 \%$. This was manifested by the passage of copious quantities of dilute urine (SG 1015 or less) with a rise of haemoglobin concentration and urea despite rehydration with intravenous isotonic saline.

\section{Inappropriate haemodilution}

This relatively uncommon but distinctive type was seen in patients who were obeying command instructions to take a copious intake of water, but who were generally recently arrived in theatre, and had been subjected to the stresses of travel, physical work and sleep deprivation shortly after arrival. Haemodilution was also seen in those with recurrent heat illness, who had been discharged with advice to drink more water. None of these patients was taking supplementary salt, and many claimed to be consuming more than 10 litres of water a day. These patients were characterised by predominantly CNS symptoms including headache, retro-orbital pain, mental confusion $(50 \%)$, loss of consciousness and fits. The blood picture was dilutional with a low serum sodium, potassium and urea concentrations, though the initial samples of urine were paradoxically concentrated (>SG1020), possibly as a result of stressinduced antidiuretic hormone secretion. 
Table 2. Percentage incidence of clinical features and mean biochemical/haematological variables (SDs in brackets) 4 principle categories of heat illness ${ }^{*}=$ significance at $<0.05$.

\begin{tabular}{|l|l|l|l|l|}
\hline & Type 1 & Type 2 & Type 3 & Type 4 \\
\hline No. overall cases & $33(41 \%)$ & $16(20 \%)$ & $5(6 \%)$ & $26(33 \%)$ \\
\hline Extreme Fatigue \% & 6 & 5 & 0 & 30 \\
\hline Dizziness & 15 & 37 & 50 & 26 \\
\hline Nausea/vomiting \% & 60 & $80^{\star}$ & 20 & 44 \\
\hline Paraesthesia \% & 6 & $50^{\star}$ & 0 & 18 \\
\hline Cramps \% & 36 & $80^{\star}$ & 0 & 29 \\
\hline Dyspnoea & 15 & 12 & 0 & 4 \\
\hline Diarrhoea & 18 & 18 & 0 & 33 \\
\hline Intestinal colic \% & 24 & $40^{\star}$ & 20 & 22 \\
\hline $\begin{array}{l}\text { Confusion, amnesia, loss } \\
\text { of consciousness \% }\end{array}$ & 0 & 18 & 50 & 85 \\
\hline Headache \% & 9 & 12 & 20 & 14 \\
\hline Pulse rate & $93(13)$ & $88(16)$ & $98(20)$ & $101(14)$ \\
\hline Systolic BP & $124(19)$ & $111(18)$ & $159(8)$ & $128(16)$ \\
\hline $\begin{array}{l}\text { Postural BP drop, } \\
\% \text { with }\end{array}$ & 60 & $100^{\star}$ & 0 & 0 \\
\hline $\begin{array}{l}\text { Reduced tissue } \\
\text { turgour \% }\end{array}$ & 41 & 37 & 0 & 0 \\
\hline $\begin{array}{l}\text { Paradoxical lack of } \\
\text { sweating \% }\end{array}$ & 5 & 18 & 0 & 81 \\
\hline Pulse pressure & 1015 & 1012 & 1022 & 1030 \\
\hline Rectal temperature & 36.8 & 36.8 & 38.2 & 38.8 \\
\hline Respiratory rate & $18(4.2)$ & $22(4.5)$ & $18.5(2)$ & $18(4)$ \\
\hline Na (135-143) & $131(5.2)^{\star}$ & $126(6)$ & $127(7)$ & $135(5)$ \\
\hline K (3.7-4-3) & $26.9(4.1)$ & $23(6.2)$ & $23(0.8)$ & $25.4(4.1)$ \\
\hline Bicarbonate (22-30) & $10.7(4.5)^{\star}$ & $19.2(6.3)^{\star}$ & $3.3(1.4)$ & $8.0(5.9)$ \\
\hline Urea (3.6-7.4) & $7.2(2.9)$ & $6.7(2.6)$ & $11.0(0.8)$ & $6.3(1.36)$ \\
\hline Glucose (3.8-6.6) & $17.8(1.7)^{\star}$ & $16.0(2.0)$ & $13.0(0.8)$ & $14.5(1.52)$ \\
\hline Hb (13-16) & $7.43(0.07)$ & $7.63(0.06)$ & $7.49(0.02)$ & $7.46(0.09)$ \\
\hline Venous pH (7.32-7.45) & $2.8(0.3)^{\star}$ & $2.65(0.4)$ & $3.4(0.5)$ \\
\hline $\begin{array}{l}\text { Urine SG, median } \\
\text { 1010-1025) }\end{array}$ & & & 78 & 55 \\
\hline
\end{tabular}

Loss of thermoregulation

The fourth type was usually seen in a setting of reduced extracellular fluid volume and progressive rise in body temperature and paradoxical cessation of sweating. These patients had often been taking strenuous exercise in hot conditions, sometimes immediately after a period of rest. Central nervous symptoms predominated, with marked fatigue followed by vomiting, dizziness and sudden impairment of consciousness. Clinical findings were a dry hot flushed skin with circumoral pallor, rectal temperature in excess of $38.5^{\circ} \mathrm{C}$, and tachycardia. The more severely affected would subsequently develop a metabolic acidosis with hyperkalaemia, myoglobinuria, elevation of creatine kinase, hepatic transaminases, and lactate dehydrogenase. Pancreatitis developed in one case, and in two an adult respiratory distress (ARDS) picture developed, requiring a period of ventilatory support.

\section{Provoking factors}

The most prevalent precipitating factor in this series was work and stress in relatively unacclimatised personnel. This was illustrated in those cases arising during a change in regiment when approximately 1100 troops arrived in theatre from the north of the UK after a period of acclimatisation of 
between 5 and 10 days. Because of operational requirements these troops experienced 4 to 6 hours travel in armoured vehicles in an external environmental temperature of $44-45^{\circ} \mathrm{C}$. Over the following $48 \mathrm{hr}$ period, 45 patients were admitted with heat illness, an incidence of about $3 \%$ of the population at risk per day (Figure 2). These troops had access to adequate supplies of water, but had not appreciated the importance of salt intake, and the biochemical picture in $58 \%$ was one of hyponatraemia, hypokalaemia with in some cases a marked respiratory alkalosis. In all cases symptoms resolved and the biochemical picture was restored to normal by the infusion of a median of 5 litres (range 3-8litres) of isotonic saline over 24 hours.

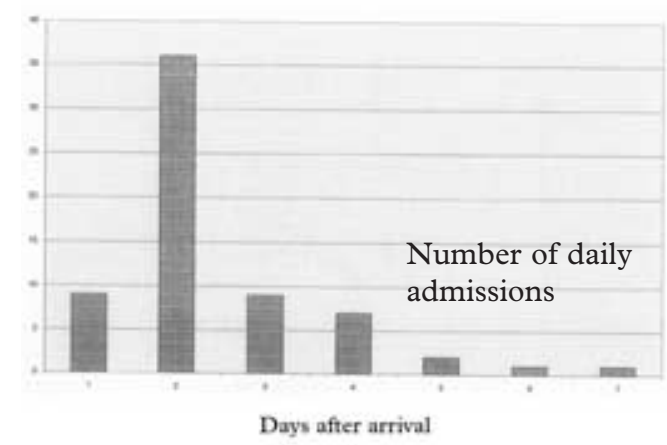

Fig 2. Daily admissions with heat-related illness following arrival of new regiment in theatre in middle of day 1 .

\section{Delayed presentation}

The onset of heat illness in relation to the time of exposure in the group of troops arriving in theatre on Op Telic is illustrated in Figure 2. The peak of admissions occurred on the second day after exposure, most of these admissions occurring during the afternoon and early evening.

\section{Late effects}

Between 1 to 2 days after presentation delayed morbidity was seen in $8 \%$ of cases. These late effects included intestinal colic seen in type 2 heat illness at 24 to 48 hours after exposure; localised tenderness and pain on movement in muscle groups, commonly abdominal wall, pectoral, deep extensor neck and diaphragm. In type 4 heat illness, reduction of glomerular filtration rate, and elevation of liver transaminases were seen in $35 \%$ of cases 2 to 4 days after heat exposure. A delayed hypokalaemia induced nephrogenic diabetes insipidus picture was seen in 4 type 2 cases. In these cases progressive haemoconcentration occurred despite massive IV fluid replacement with saline and in the presence of a diuresis of dilute urine (SG<1012).

\section{Delayed acclimatisation}

Four percent of the admissions over the study period remained chronically unwell despite attempts to re-acclimatise. Repeated admissions occurred until they were eventually returned home. These patients were significantly more obese (mean body mass 28.4 cf $21 \mathrm{p}<0.05$ ) and older (mean age 35 cf $21.5 \mathrm{p}<0.05$ ) than the patients not requiring repeated re-admission. The present data would not distinguish between the effects of age and those of obesity.

\section{Discussion}

Previous publications on heat illness have tended to focus on thermoregulatory malfunction $(1,2)$, which, is a dramatic, and potentially, the most dangerous presentation. This is the most important cause of heatrelated illness in the military in temperate climes. The medical literature also makes reference to heat cramps, heat syncope, heat exhaustion, and water depletion heat exhaustion, and these syndromes are well described in the older textbooks (4).

However, the present study suggests that the pathological response of the body to high environmental temperatures more commonly commences with a reduction of extracellular fluid (ECF) volume caused by excessive sodium loss in non-acclimatised sweat (3) (Figure 3). We did not measure ECF volume directly, but assume that it was reduced on the basis of the low serum sodium concentrations observed combined with the physical signs of ECF depletion. The reduction in ECF volume in turn leads to impaired heat loss (5). The reduction in ECF and secondary loss of plasma volume causes loss of tissue turgour and hypovolaemia, whilst the associated electrolyte changes give rise to gastrointestinal (GI) and neuromuscular symptoms. We have called this Type 1 heat illness. It is conjectured that as ECF and plasma volume fall there is secondary activation of the renin/aldosterone system with eccrine and renal conservation of sodium and potassium loss (6). During the process of acclimatisation the sweat becomes steadily less salty as the sweat glands become more sensitive to aldosterone (5), though there is some inter-individual variation in the rate at which this takes place. The acclimatisation process is accelerated by regular moderate exercise (7). Some individuals remain heat intolerant despite efforts to acclimatise (8). This group of patients is generally older and more obese than those presenting with acute symptoms. They represent $4 \%$ of our cases. In others, the response to heat involves hyperventilation, just as some animals tend to pant in response to heat. These subjects present with symptoms of agitation, dyspnoea, and paraesthesia and the biochemical picture is one of more or less compensated respiratory alkalosis and marked hypokalaemia; we have named this Type 2 heat illness. In a further small proportion we see a mainly dilutional picture (Type 3).

Thirst is largely mediated by osmolar 


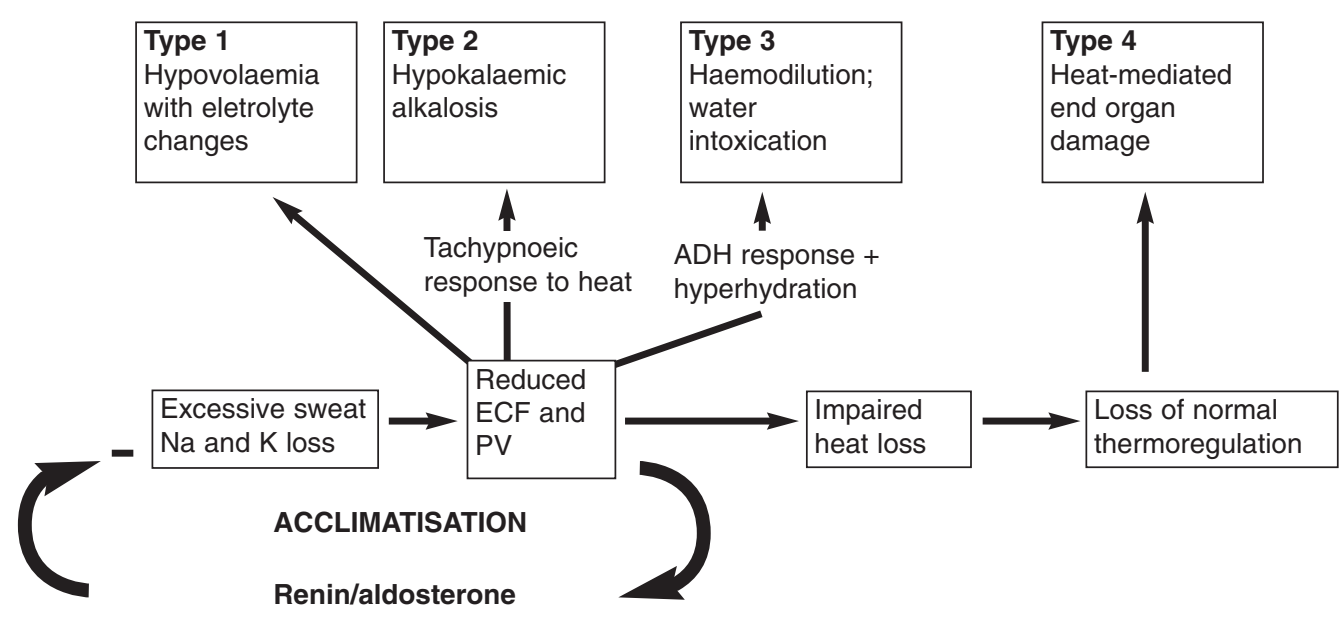

Fig 3. Mechanisms in heat illness.

changes in the cerebrospinal fluid (11), and for that reason is not a feature in Type 1 or 2 heat illness cases where the fluid loss is isoosmotic. The symptoms are predominantly GI and neuromuscular. Because GI symptoms are the presenting feature in so many cases, infective diarrhoea and vomiting may be incorrectly diagnosed. This is an understandable error as the circumstances in which heat illness arises in a deployed force are also likely to be associated with a high incidence of diarrhoeal illness. What characterises heat illness as the cause of the GI symptoms is the immediate resolution of the symptoms following adequate rehydration with intravenous saline. The diagnosis of infective diarrhoea and vomiting is not always erroneous: Type 4 heat illness may be precipitated by anything, including an incidental GI upset, which causes a reduction of ECF volume (5), so there is a good deal of diagnostic overlap. In both instances, replacement of fluid and electrolyte deficits is the mainstay of treatment, but the rectal or tympanic membrane temperature should be monitored in all cases where heat illness is a possibility, and active cooling measures instituted when this exceeds $38.5^{\circ} \mathrm{C}$.

\section{Prevention}

Prevention of Types 1 and 2 heat-illness is largely a matter of acclimatisation, avoidance of over-exposure to heat and humidity, additional salt intake and regular gentle exercise $(3,6,7)$. Salt intake mediates the thirst response and provides the osmotic skeleton whereby water can be maintained within the extracellular fluid compartment. During heat acclimatisation it has been shown that increasing the normal dietary intake of salt by a factor of about 4 prevents the negative sodium balance, plasma volume contraction and cell swelling which otherwise occurs (12). We found that a $2.5 \mathrm{~g}$ sachet of salt added to a 1.5 litre bottle of drinking water with a dash of fruit juice concentrate produces a palatable drink which, when taken in quantities sufficient to ensure an abundant flow of almost colourless urine, combined with a re-acclimatisation schedule, prevented the need for readmission in all but the chronically heat-intolerant $4 \%$ of our cases. The importance of avoiding heat stress in recently arrived individuals is well illustrated by the peak in admissions following the introduction of new troops into theatre (Figure 2). The practice of arriving in the heat of the day and immediately undertaking heavy physical work unloading vehicles, putting up tents etc., is to be avoided if possible. Immediate rest on arrival followed by the introduction of graded exercise in the cool of the early morning would be preferable, and this may involve organising things so that those arriving are assisted by those already acclimatised. Prevention of Type 3 heat illness is a question of avoiding additional stressors, and the provision of adequate supplies of salt as well as water over the acclimatisation period. Hyperhydration should be avoided; it does not accelerate acclimatisation and increases the risk of water intoxication $(9,10)$. Prevention of Type 4 heat illness involves avoiding sudden over-exertion in the heat of the day, and the recognition that physical fitness provides no protection. Exercise after sleep and fasting when unwell or when recovering from a previous bout of heat illness should be forbidden. Potential victims should be made aware of the dangers of this condition which carries a substantial mortality rate (13) and advised to desist from exercise and immediately seek cooling if they find themselves developing the characteristic symptoms (Table 1 ).

\section{Recognition and management}

Early detection is important: it may be difficult to distinguish between the mildly ill and the more severely ill but apparently well. Many individuals with fairly mild symptoms have grossly abnormal sodium and potassium concentrations or evidence of marked haemoconcentration, whereas others with similar symptoms turn out to have no 
clinical or biochemical abnormality. Both the clinical and the haematological-biochemical picture should be taken into account when making treatment decisions and patients should be advised to seek medical advice at an early stage, when symptoms such as fatigue, muscle cramps, diarrhoea, paraesthesia, nausea or vomiting first present. Heat-related illness should be anticipated within the first 24-48 hours whenever partially acclimatised individuals arrive in a hot or humid area. Gastrointestinal symptoms including vomiting and diarrhoea may be the dominant feature.

Type 4 heat illness often arises in a setting of Type 1 or 2 heat illness, but may arise de novo in a patient previously entirely asymptomatic. Underlying contraction of extracellular fluid volume appears to be a precipitating event in many cases (5) (Figure 3). These patients often pride themselves on their fitness and may present after having taken competitive exercise in the heat of the day. Fatigue is a predisposing factor (8). The period just prior to the exercise has sometimes been spent asleep and not drinking. Supervising staff should be made aware of the danger signs, - dry, hot, flushed skin with perioral pallor, conjunctival injection, or vomiting. They should be instructed to take immediate action to cool the patient down and seek medical help as soon as any of these signs appear. Those individuals who fail to heat adapt remain permanently fatigued and prone to bouts of GI dysfunction, cramps and paraesthesia. Repeated admissions occur, and it is probably as well to recognise these generally slightly older and more obese individuals at the time of their second or third attendance and send them to a temperate zone without further delay.

Taking all the above measures into consideration, it appears that many of the patients that we saw with heat related-illness might have avoided it by taking a few simple steps. These include appreciating that there is a period of acclimatisation lasting 7 to 10 days in most people. During this period vigorous work in the heat of the day is to be avoided if possible; gentle exercise should be taken during the cool periods and extra salt should be consumed to increase the salt intake to $15-20$ grams, with just sufficient water to relieve thirst and to ensure the flow of clear or slightly coloured urine.

\section{In-patient treatment}

Treatment with basic first aid measures, intravenous saline and cooling is applicable to all forms of heat illness. This includes the ABCs of resuscitation. In types 1 and 2 heat illness, pyrexia is often not the major feature and treatment should be directed at correcting the salt and water deficiency with copious quantities of cold intravenous isotonic saline. The deficiency in extracellular fluid volume may be judged by the degree of haemoconcentration; as a rule of thumb for an average adult we would give 1.0 litre of saline per 1 -gm rise in haemoglobin concentration above $15 \mathrm{G} \%$ and would aim to correct the fluid deficit within 4 to 6 hours, whilst at the same time making allowance for normal fluid requirements, bearing in mind that under sub-tropical conditions, insensible losses amount to $1500-2000 \mathrm{mls}$ per day. Some people seem to physiologically heat-adapt despite evidence of sustained haemoconcentration. Our control group of symptom-free individuals demonstrated a bimodal distribution of haematocrit, $80 \%$ falling into the range 40 $47 \%$ whilst $20 \%$ had a haematocrit of $>55 \%$. Acid/base and potassium abnormalities tend to correct themselves following adequate intravenous therapy with isotonic saline, though in our series, cases in which the serum potassium was reduced below $3.0 \mathrm{mM} / \mathrm{L}$, supplementary IV potassium chloride was administered at a rate of $20 \mathrm{mM} / \mathrm{hr}$ with ECG monitoring until the potassium deficiency was corrected. Cases of Type 2 heat illness presenting with agitation, hyperventilation and tetany, or muscle spasms, have a respiratory alkalosis and rebreathing into a large paper bag palliates the symptoms. Chlorpromazine in a dose of $10-20 \mathrm{mgm}$ IV is useful for its sedative, antinauseant and vasodilator properties. In dilutional Type 3 heat illness, intravenous fluid therapy with hypertonic saline is indicated. Additional supportive measures may be required in Types 3 and 4 heat illness where loss of consciousness, fits, respiratory arrest and multi-organ disease including ARDS, disseminated intravascular coagulation, and fits may occur. In Type 4 disease cooling is urgent; once the core temperature rises above $39-40^{\circ} \mathrm{C}$, a progressive evolving illness with a high risk of multiorgan failure is likely to occur $(14,15)$. Rectal temperature should not be used as a sole guide to management as high core temperatures may fall prior to admission (1). The patient may appear relatively well following initial cooling but will then go on to develop a serious illness commonly featuring evidence of renal and hepatic damage, lactic acidosis, rhabdomyolysis, hyperkalaemia, an ARDS type syndrome, cerebral and cerebellar damage, and disseminated intravascular coagulation. A number of measures for rapid cooling have been proposed, but the most practical and effective in field conditions remains spraying with tepid water and fanning (13). Initial hypokalaemia and metabolic alkalosis may change over the first few hours to a picture of hyperkalaemia and metabolic acidosis (17). Established adverse prognostic indicators include rising temperature despite measures aimed at cooling, hypotension, acidosis, hyperkalaemia, and elevated LDH (17). 
These patients require admission and monitoring in an HDU/ITU type facility. There is a significant early and late mortality.

\section{References}

1. Dickinson JG. Exertional heat stroke - history and epidemiology: definitions and groups at risk. In: Hopkins PM Ellis FR eds. Hyperthermic and hypermetabolic disorders. Cambridge: Cambridge University Press 1996; 3-19.

2. Defence Medical Services. Climatic injuries in the armed forces: prevention and treatment. Foint Services Publication 539, Jan 2003.

3. Allan JR Wilson CG. Influence of acclimation on sweat sodium concentration. F Appl Physiol 1971: 30(5): 708-12.

4. Leithead CS. Heat Stress and Heat Related Disorders. Cassell, London 1964.

5. Fortney SM, Nadel ER, Wenger CB, et al. Effect of blood volume on sweating rate and body fluids in humans. F Appl Physiol 1981; 51(6): 1594-600.

6. Kirkby CR, Convertino VA. Plasma aldosterone and sweat sodium concentration after exercise and heat acclimation. F Appl Physiol 1986: 61(3): 967-70.

7. Fukumoto T, Tanaka T, Fujaka H, et al. Differences in composition of sweat produced by thermal exposure and by running exercise. Clin Cardiol 1988; 11(10): 707-9.

8. Armstrong LE, DeLuca JP, Hubbard RW. Time course of recovery and heat acclimation ability of prior exertional heat stroke patients. Med Sci Sports Exerc 1990; 22(1): 36-48.
9. Latzka WA, Shenka MN, Montain SJ, et al. Hyperhydration: thermoregulatory effects during compensable exercise heat-stress. I App Physiol 1997; 83(3): 860-6.

10. Noakes TD, Goodwin N, Rayner BL. Water intoxication: a possible complication during endurance exercise. Med Sci Sports Exerc 1985; 17(3): 370-5

11. Stricker EM, Sved AF. Thirst. Nutrition 2000; 16(10): 821-6

12. Armstrong LE, Costill DL, Fink WJ. Changes in body water and electrolytes during heat acclimation: effects of dietary sodium. Aviat Space Environ Med 1987; 58(2): 143-8.

13. Bouchama A. Heatstroke: a new look at an ancient disease. Intensive Care Med 1995; 21: 623-5.

14. Shahid MS, Hatle L, Mansour $\mathrm{H}$, et al. Echocardiographic and Doppler studies of patient with heat stroke and heat exhaustion. Int $\mathcal{F}$ Cardiac Imaging 1999; 15: 279-85.

15. Dermatte JE, OíMara K, Buescher J et al. Nearfatal heat stroke during the 1995 heat wave in Chicago. Ann Int Med 1998; 129: 173-81.

16. Grogan H, Hopkins PM. Heat stroke: implications for critical care and anaesthesia. Brit $\mathcal{f}$ Anaesth 2002; 88(5): 700-7.

17. Alzeer AH, El-Hazmi MAF, Warsy AS, et al. Serum enzymes in heat stroke: prognostic implication. Clin Chem 1997; 43: 1182-7. 